\title{
Resistin Exacerbates Insulin Resistance under the Condition of Low Adiponectin in 3T3-L1 Adipocytes
}

\author{
Noritaka Machii, Hiroaki Satoh*, Akihiro Kudoh and Tsuyoshi Watanabe
}

Department of Nephrology, Hypertension, Diabetology, Endocrinology and Metabolism, Fukushima Medical University, Japan

\begin{abstract}
Adipocytokines such as resistin, TNF-a, and adiponectin, which are adipocyte-derived peptides, play important roles in glucose metabolism. Resistin and TNF- $\alpha$ have been implicated as factors associated with the development of insulin resistance in obesity. In contrast, adiponectin has been shown to improve insulin sensitivity in insulin resistance. However, the interaction among these adipocytokines is still unknown. In this study, we investigated the mechanism of the effects of these 3 adipocytokines (resistin, adiponectin, and TNF- $\alpha$ ) on glucose transport in 3T3-L1 adipocytes.

Glucose uptake was evaluated by 2-[3H] deoxy-glucose (DOG) uptake assay in 3T3-L1 adipocytes. Resistin and adiponectin secretion were analyzed by western blotting.

Adenovirus-mediated overexpression of resistin inhibited insulin-stimulated 2-DOG uptake by only $15 \%$ compared with control cells. In contrast, pretreatment of cells with $10 \mathrm{ng} / \mathrm{mL}$ TNF- $\alpha$ for $3 \mathrm{hrs}$ did not inhibit insulin stimulated 2-DOG uptake compared with control cells, whereas overexpression of resistin led to a $\sim 40 \%$ decrease in insulin stimulated 2-DOG uptake following pretreatment with TNF- $\alpha$. TNF- $\alpha$ has been shown to suppress the expression and secretion of adiponectin from adipocytes. Therefore, we speculated that this potentiating effect of resistin might be caused by the reduction in adiponectin secretion. We confirmed that the secretion of adiponectin was decreased by $\sim 50 \%$ in TNF- $\alpha$ treated cells compared to control cells. Furthermore, overexpression of adiponectin prevented this additive effect of resistin and TNF- $\alpha$
\end{abstract}

In conclusion, these results suggest that: (1) TNF- $\alpha$ enhances the action of resistin via the reduction of adiponectin, 2) Resistin may cause severe insulin resistance under low adiponectin levels.

Keywords: Resistin; Adiponectin; TNF- $\alpha$

Abbreviations: TNF- $\alpha$ : Tumor Necrosis Factor- $\alpha$; AMPK: Activated Protein Kinase; Ad-resistin: Resistin Adenovirus; Adadipo: Adiponectin Adenovirus; Ad-lacZ: lacZ Adenovirus; 2-DOG: 2-deoxyglucose; IR: Insulin Receptor; IRS-1: Insulin Receptor Substrate 1

\section{Introduction}

Obesity is linked to common metabolic diseases including insulin resistance, which constitutes a principal risk factor for type 2 diabetes. Accumulating evidence indicates that changes in adipose-secreted factors in obesity, including release of inflammatory cytokines, dramatically affect insulin sensitivity [1-3].

Resistin is a $12.5 \mathrm{kDa}$ cysteine-rich polypeptide discovered in a screen for adipocyte gene products that are downregulated by antidiabetic thiazolidinedione drugs [4]. Resistin serum levels increase in diet-induced and genetic models of obesity [4], although adipose tissue mRNA levels are reduced $[5,6]$. Systemic treatment or transgenic overexpression of resistin in rodents decreases the ability of insulin to suppress hepatic glucose production [7,8]. Conversely, ablation of the resistin gene or reduction in resistin protein through antisense oligonucleotide treatment improves insulin sensitivity through AMP-activated protein kinase (AMPK) activation $[9,10]$. The resistin receptor is not known but the effect of resistin inducing insulin resistance is associated with attenuation of AMPK phosphorylation [810]. Human resistin is made and secreted by macrophages [11]. Plasma resistin levels and single-nucleotide polymorphisms has been linked to obesity and lipid and glucose abnormalities in some studies [12-15], although others have failed to establish such a relationship [16].

On the other hand, adiponectin [17-20] is a hormone secreted by adipocytes, which functions as the key antidiabetic and anti-atherogenic adipocytokine [21]. Plasma adiponectin levels are decreased in obesity, insulin resistance, and type 2 diabetes mellitus [22]. Many studies have shown that high levels of adiponectin are associated with insulin sensitization, whereas low levels are found in insulin resistance [2327]. This insulin-sensitizing effect of adiponectin is mediated by the inhibition of gluconeogenesis [27] and the stimulation of fatty acid oxidation [25,26] via activation of AMPK [28]. In contrast, TNF- $\alpha$, an adipocyte-tissue derived peptide, is markedly elevated in obese or diabetic animals and humans [29]. In a mouse model, adiponectin deficiency was associated with severe diet-induced insulin resistance and elevated TNF- $\alpha$ levels by not resistin levels [30]. Thus, adiponectin and TNF- $\alpha$ are reciprocally expressed in adipocytes and have opposing effects on the regulation of insulin resistance. However, the interaction among these 2 adipokines and resistin is still unknown.

In this study, we investigated the mechanism of the effects of these adipocytokines on glucose transport in 3T3-L1 adipocytes.

*Corresponding author: Hiroaki Satoh, Department of Nephrology, Hypertension, Diabetology, Endocrinology and Metabolism, Fukushima Medical University, Hikarigaoka Fukushima City, Fukushima, 960-1295, Japan, Tel: +81-24-547-1206 Fax: +81-24-548-3044; E-mail: hiroakis-tky@umin.ac.jp

Received November 13, 2012; Accepted December 18, 2012; Published December 23, 2012

Citation: Machii N, Satoh H, Kudoh A, Watanabe T (2012) Resistin Exacerbates Insulin Resistance under the Condition of Low Adiponectin in 3T3-L1 Adipocytes. J Diabetes Metab 3: 230. doi:10.4172/2155-6156.1000230

Copyright: $\odot 2012$ Machii N, et al. This is an open-access article distributed unde the terms of the Creative Commons Attribution License, which permits unrestricted use, distribution, and reproduction in any medium, provided the original author and source are credited. 


\section{Materials and Methods}

\section{Materials}

3T3-L1 preadipocytes were purchased from American Type Cell Collection (Manassas, VA, USA). pAxCAwt plasmid vector was purchased from TAKARA Biomedical (Shiga, Japan). Dulbecco' modified Eagle's medium (DMEM, high glucose), streptomycin, trypsin, fetal bovine serum, TRIzol reagent, pCR2.1-TOPO vector, lithium dodecyl sulfate sample buffer, and Sample Reducing Agent were purchased from Invitrogen (Carlsbad, CA, USA). The RNeasy kit was purchased from QIAGEN Inc. (Valencia, CA, USA). Mouse TNF- $\alpha$ was purchased from R\&D System (Minneapolis, MN, USA). Anti-resistin antibody (ab93069) was purchased from Abcam (Tokyo, JAPAN). Anti-adiponectin antibody was purchased from Affinity BioReagents, (Golden, CO, USA). Polyvinylidene difluoride (PVDF) transfer membranes were purchased from Millipore Corp. (Bedford, MA, USA). iScript cDNA Synthesis Kit and iQ SYBR Green Supermix were purchased from Bio-Rad Laboratories (Richmond, CA, USA). $2-\left[{ }^{3} \mathrm{H}\right]$ deoxyglucose (DOG) was purchased from PerkinElmer Inc. (Waltham, MA, USA). Adiponectin was purchased from Affinity BioReagents (Golden, CO, USA)

\section{Subcloning of the mouse resistin and adiponectin cDNA by RT-PCR}

Total RNA was extracted from differentiated 3T3-L1 adipocytes using TRIZOL reagent (Invitrogen). Briefly, $1 \mathrm{~g}$ of total RNA was reversetranscribed with $200 \mathrm{U}$ of reverse transcriptase using the Superscript ${ }^{\mathrm{TM}}$ II kit (Invitrogen) according to the manufacturer's recommendations. The mouse resistin cDNA (359 bp) and full-length adiponectin cDNA (765 bp) were amplified using the 5'-GTACCCACGGGATGAAGAACC-3' sense and 5'-ACATCAGGAAGCCTGCAG-3' antisense primers, and the 5'-CAGGATGCTACTGTTGCAAGC-3' sense and 5'-TGGGTAGTTGCAGTCAGTTGG-3' antisense primers, respectively. PCR products were separated on a $2 \%$ agarose gel and purified using the Qiaquick PCR Purification Kit (QIAGEN, Valencia, $\mathrm{CA}$ ). The mouse resistin CDNA and adiponectin CDNA were thereafter subcloned into the pCR2.1-TOPO (Invitrogen), respectively, and sequenced to confirm that the clones corresponded to mouse resistin (GenBank $^{\mathrm{TM}}$ accession number AF323080) and mouse adiponectin (GenBank $^{\mathrm{TM}}$ accession number AF304466).

\section{Construction of recombinant adenoviruses}

Resistin adenovirus (Ad-resistin), adiponectin adenovirus (Adadipo), and lacZ adenovirus (Ad-lacZ) were generated and purified using a previously described protocol [8]. Briefly, the mouse resistin cDNA was inserted in the pAxCAwt plasmid to generate pAxCAwtmouse resistin. The resulting plasmid, which contains the resistin cDNA under the control of a CAG promoter (CMV enhancer, chicken $\beta$-actin promoter, and parts of an untranslated region of rabbit $\beta$-globin), was transfected into HEK 293 cells. Recombinant adenovirus from a single plaque was propagated in HEK 293 cells and purified with Adeno-X Virus Purification and Rapid Titer Kits (TAKARA BIO INC, Shiga, JAPAN). Ad-adipo and control Ad-lacZ, which carries the $\beta$-galactosidase cDNA were isolated using the same procedure, respectively. These recombinant viruses were dialyzed in phosphatebuffered saline, $\mathrm{pH} 7.4$, and stored in $10 \%$ glycerol/phosphate-buffered saline at $-80^{\circ} \mathrm{C}$ until use.

\section{Cell culture and cell treatment}

3T3-L1 cells were cultured and differentiated as described previously [31]. For adenovirus infection, differentiated 3T3-L1 adipocytes were transduced for $2 \mathrm{hrs}$ in DMEM (high glucose) with 2\% heat-inactivated fetal bovine serum with recombinant adenovirus of resistin, or/and, adiponectin, or/and control recombinant adenovirus of lacZ. Transduced cells were incubated for $48 \mathrm{hrs}$ at $37^{\circ} \mathrm{C}$ in $10 \% \mathrm{CO}$ and DMEM (high glucose) with $10 \%$ heat-inactivated serum, followed by incubation in starvation media required for the assays.

\section{2-Deoxyglucose uptake assay}

Glucose uptake was initiated as described previously [31], with some modifications. After $48 \mathrm{hrs}$ of adenovirus infection, 3T3-L1 adipocytes were serum-starved for $6 \mathrm{hrs}$ and then stimulated with $100 \mathrm{ng} / \mathrm{mL}$ insulin in KRP-HEPES buffer (10 mM HEPES, $\mathrm{pH} 7.4$, $131.2 \mathrm{mM} \mathrm{NaCl}, 4.7 \mathrm{mM} \mathrm{KCl}, 1.2 \mathrm{mM} \mathrm{MgSO}, 2.5 \mathrm{mM} \mathrm{CaCl}_{2}, 2.5$ $\mathrm{mM} \mathrm{NaH} \mathrm{PO}_{4}$ ) for $30 \mathrm{~min}$ at $37^{\circ} \mathrm{C}$. Glucose uptake was determined in triplicate at each point after the addition of $2-\left[{ }^{3} \mathrm{H}\right]$ DOG $(0.1 \mu \mathrm{Ci}$, final concentration $0.1 \mathrm{mM}$ ) in KRP-HEPES buffer for $5 \mathrm{~min}$ at $37^{\circ} \mathrm{C}$. The cells were washed 3 times in ice-cold phosphate-buffered saline and solubilized in $1 \mathrm{~N} \mathrm{NAOH}$. Each sample was subjected to liquid scintillation counting [31].

\section{Immunoblotting analysis}

Differentiated 3T3-L1 adipocytes were transduced with Adresistin, Ad-adipo, or/and Ad-lacZ. At $48 \mathrm{hrs}$ after infection, 3T3-L1 adipocytes were starved for $3 \mathrm{hrs}$ prior to treatment without or with TNF- $a(10 \mathrm{ng} / \mathrm{mL})$ for $3 \mathrm{~h}$. Conditioned medium was then collected. For western blot analysis, condition medium (10 $\mu \mathrm{L}$ per lane) was denatured by boiling in lithium dodecyl sulfate sample buffer and Sample Reducing Agent (Invitrogen), and then fractionated by sodium dodecyl sulfate-polyacrylamide gel electrophoresis. Gels were transferred to a polyvinylidene difluoride membrane (Immobilon-P), using a semi-dry Transblot apparatus (Bio-Rad Laboratories Inc.). For immunoblotting, membranes were blocked and probed with resistin (Abcam) or adiponectin (Affinity BioReagent) antibodies. Membranes were then incubated with horseradish peroxidase-conjugated secondary antibodies before chemiluminescence detection, according to the manufacturer's instructions (Pierce, Rockford, IL, USA). Band intensities were quantified by densitometry using the Image J software (NIH, USA).

\section{Statistical analysis}

Statistical analysis were performed using Excel statistics 2008 (SSRI, Tokyo, Japan) added in Excel software (Microsoft Corporation, USA). The data were analyzed by one-way ANOVA or unpaired two-tailed Student $t$ test. A $P$-value of less than 0.05 was considered to indicate significance. All values are expressed as mean \pm SE.

\section{Results}

\section{Resistin inhibits insulin-stimulated 2-DOG uptake in 3T3-L1 adipocytes}

We first examined the effects of resistin overexpression on insulinstimulated glucose uptake in 3T3-L1 adipocytes. As shown in figure 1 , overexpression of resistin by Ad-resistin led to a $15 \%$ decrease $(P<0.05)$ in insulin $(100 \mathrm{ng} / \mathrm{mL})$-stimulated 2-DOG uptake, whereas resistin did not induce any change in basal 2-DOG uptake.

\section{TNF- $\alpha$ exacerbates the effect of resistin on insulin-stimulated} 2-DOG uptake in 3T3-L1 adipocytes

Pretreatment of cells with $10 \mathrm{ng} / \mathrm{mL}$ TNF- $\alpha$ for $3 \mathrm{hrs}$ did not inhibit insulin stimulated 2-DOG uptake compared with control cells, whereas 
overexpression of resistin led to an approximately $40 \%$ decrease $(P<0.01)$ in insulin $(100 \mathrm{ng} / \mathrm{mL})$-stimulated 2-DOG uptake following pretreatment with TNF- $\alpha$ (Figure 2).

TNF- $\alpha$ suppresses the secretion of adiponectin from 3T3-L1 adipocytes

TNF- $\alpha$ has been reported to suppress the expression and secretion of adiponectin from adipocytes. It has been known that adiponectin is an insulin-sensitizing hormone, which is also secreted from adipocytes. We, therefore, speculated that the glucose uptake-suppressing effect of resistin that is induced by TNF- $\alpha$ may be caused by the reduction of adiponectin. To prove this, we confirmed whether TNF- $\alpha$ suppresses the secretion of adiponectin in 3T3-L1 adipocytes by western blotting analysis. The supernatants after treatment with or without TNF- $\alpha$ for 3 hrs were used as samples. As shown in figure 3, TNF- $\alpha$ suppressed the secretion of adiponectin in 3T3-L1 whether resistin was overexpressed or not.

Overexpression of adiponectin prevented the synergic effect of resistin and TNF- $\alpha$ in 3T3-L1 adipocytes

Next, we investigated whether this effect is improved by the

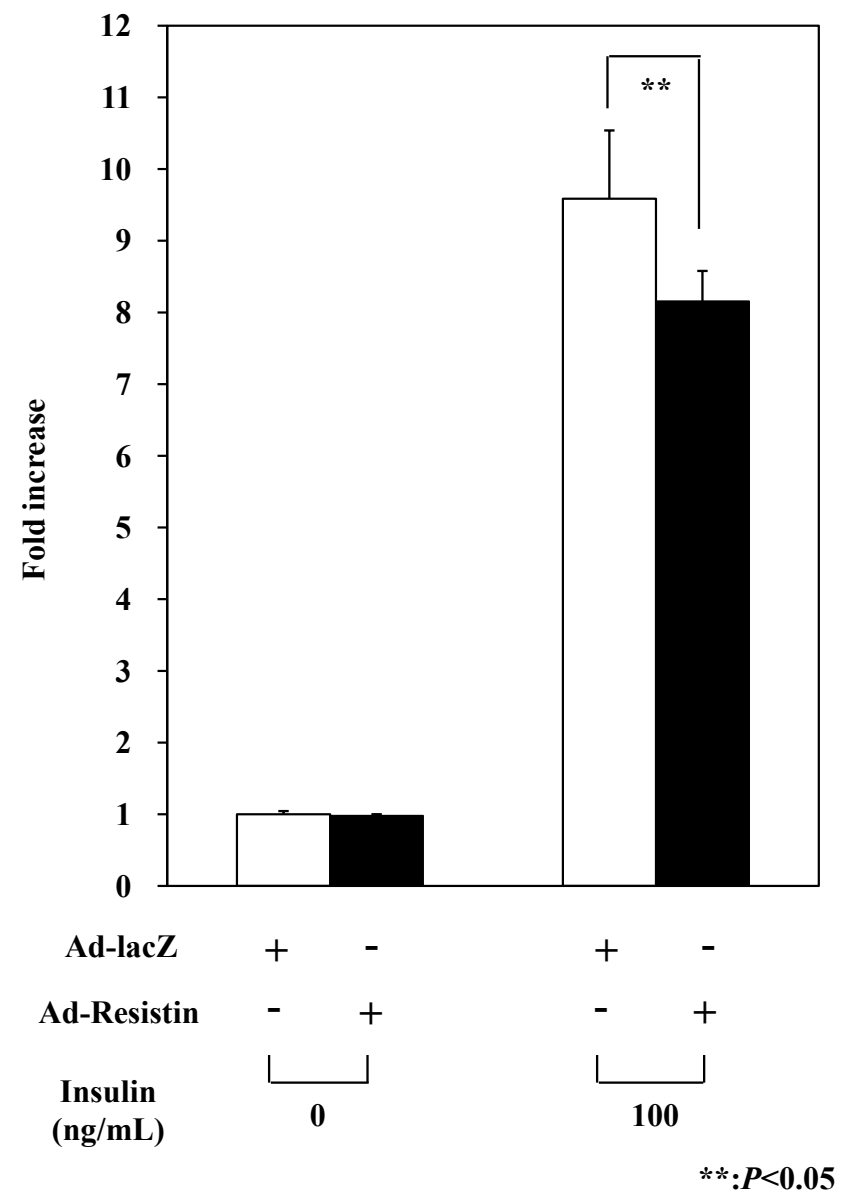

Figure 1: Resistin inhibits insulin-stimulated 2-DOG uptake in 3T3-L1 adipocytes. 3T3-L1 adipocytes were transduced with Ad-resistin or Ad-lacZ. At $48 \mathrm{hrs}$ after infection, serum-starved 3T3-L1 adipocytes were treated with insulin $(100 \mathrm{ng} / \mathrm{mL})$, followed by measurement of 2-DOG uptake. Data represent the mean \pm SE of 3 independent experiments (each experiment was performed with 6 samples). ${ }^{*} P<0.05$.

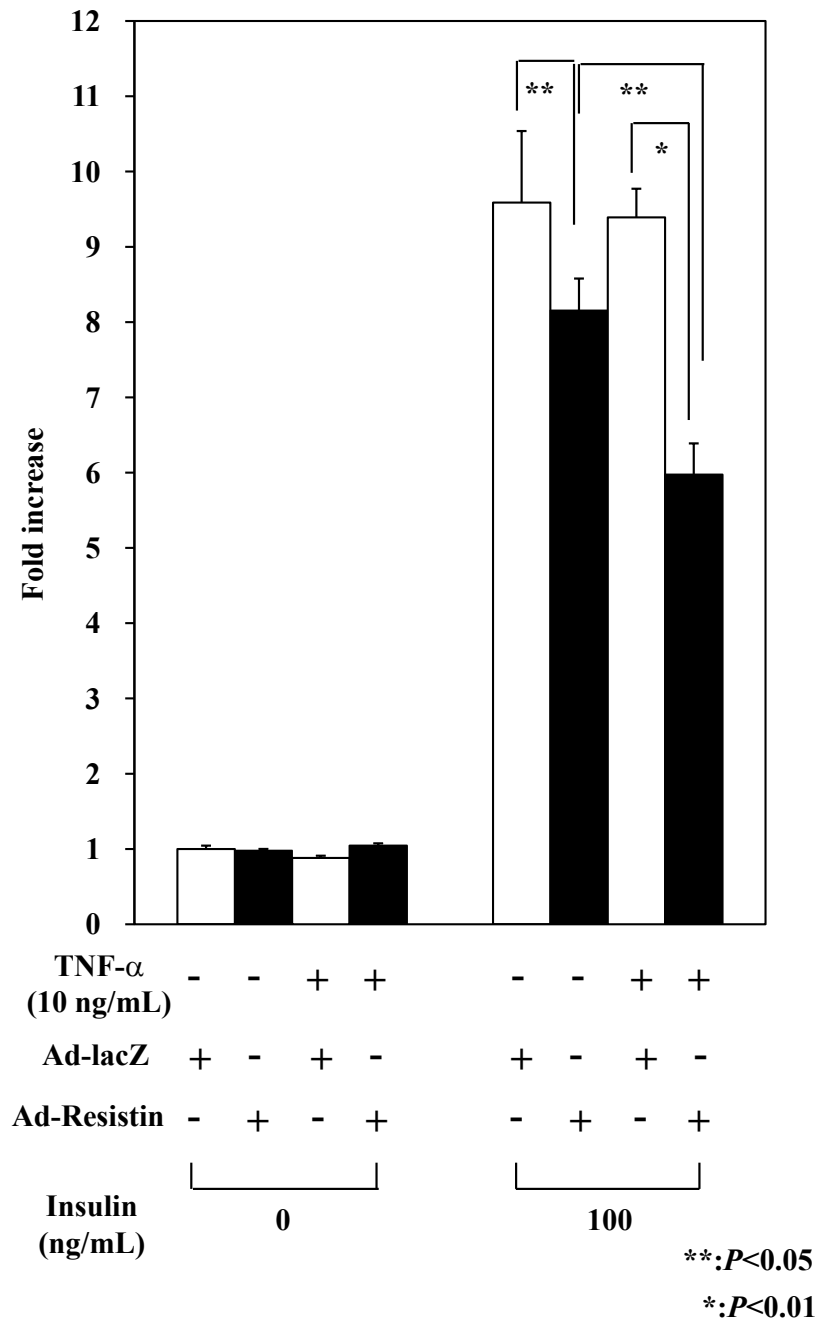

Figure 2: TNF- $\alpha$ exacerbates the effect of resistin on insulin-stimulated 2-DOG uptake in 3T3-L1 adipocytes. 3T3-L1 adipocytes were transduced with Ad-resistin or Ad-lacZ. At 48 hrs_after infection, serum-starved 3T3$\mathrm{L} 1$ adipocytes were treated without or with TNF- $\alpha(10 \mathrm{ng} / \mathrm{mL})$ for $3 \mathrm{~h}$. These 3T3-L1 adipocytes were treated with insulin $(100 \mathrm{ng} / \mathrm{mL})$, followed by measurement of 2-DOG uptake. Data represent the mean \pm SE of 3 independent experiments (each experiment was performed with 6 samples). ${ }^{\star} P<0.05,{ }^{* *} P<0.01$

overexpression of adiponectin. The overexpression of adiponectin prevented the resistin and TNF- $\alpha$ induced inhibition of insulinstimulated 2-DOG uptake (Figure 4). Thus, the TNF- $\alpha$-induced effect of resistin is improved by the overexpression of adiponectin.

Reduced adiponectin secretion by treatment with TNF- $\alpha$ is rescued by infection of 3T3-L1 adipocytes with Ad-adipo

Furthermore, we examined the adiponectin levels by western blotting analysis. For this, we collected the supernatants of cells overexpressing resistin or both adiponectin and resistin after treatment with or without TNF- $\alpha$ for $3 \mathrm{~h}$. The adiponectin levels, which were decreased by TNF- $\alpha$ treatment, improved by the overexpression of adiponectin (Figure 5).

\section{Discussion}

The major finding of this study is that low adiponectin levels leads to 

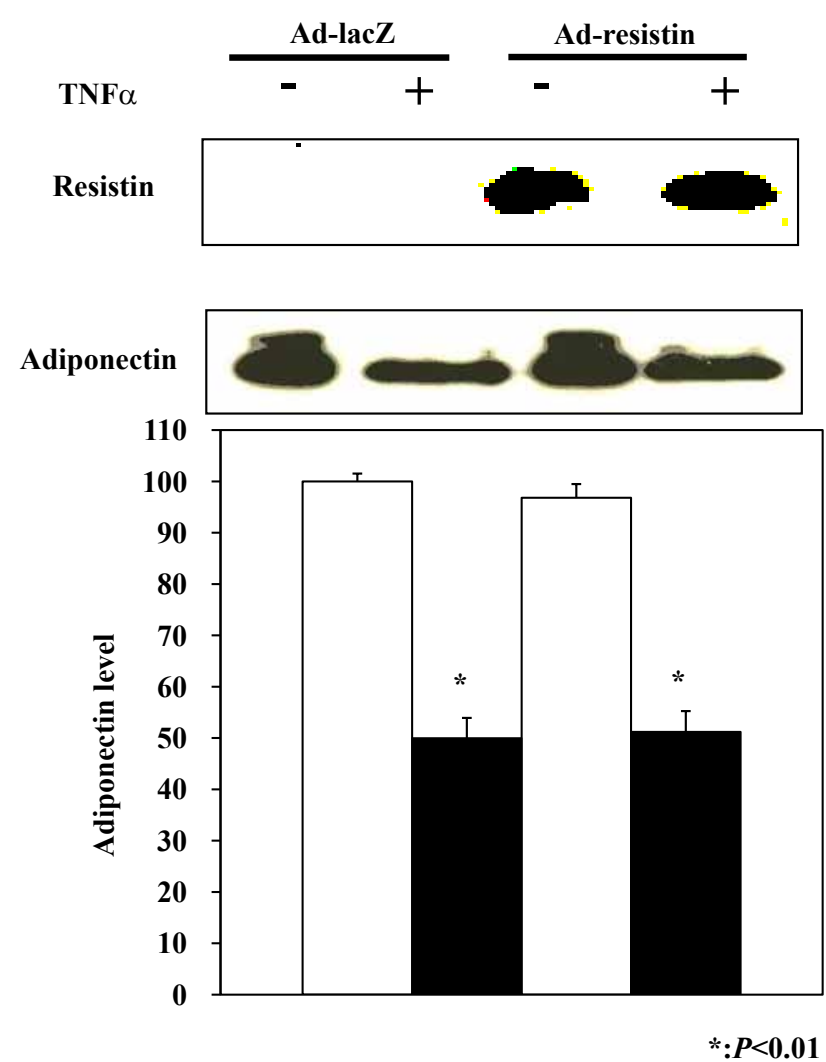

Figure 3: TNF- $\alpha$ suppresses the secretion of adiponectin from 3T3-L1 adipocytes. 3T3-L1 adipocytes were transduced with Ad-resistin or AdlacZ. At $48 \mathrm{hrs}$ after infection, 3T3-L1 adipocytes were serum-starved for 3 hrs prior to treatment without or with TNF- $\alpha(10 \mathrm{ng} / \mathrm{mL})$ for $3 \mathrm{~h}$. Conditioned medium was then collected, and fractionated by sodium dodecyl sulfatepolyacrylamide gel electrophoresis, and immunoblotted using a polyclonal antibody against mouse adiponectin or mouse resistin determining the levels of secreted adiponectin or resistin. Relative levels of adiponectin released from adipocytes treated with TNF- $\alpha$, as assessed from 4 independent experiments. ${ }^{* *} P<0.01$

the exacerbation of resistin-induced insulin resistance. Our data show that resistin exacerbates the insulin-stimulated glucose uptake under the condition of low adiponectin levels in 3T3-L1 adipocytes. Resistin is upregulated in obese states model [4], and systemic treatment or transgenic overexpression of resistin in rodents decreases the ability of insulin to suppress hepatic glucose production $[7,8]$. In some human studies, plasma resistin levels and single-nucleotide polymorphisms have been linked to obesity and lipid and glucose abnormalities [1215], while in some others was not [16]. Thus, the action of resistin in humans is controversial. The reason for the discrepancy in the effect of resistin in many human studies is not yet understood. As a speculation, it could be mentioned, that altered adiponectin levels could lie behind these discrepancies, based on this study.

On the other hand, adiponectin, which has an opposing effect to resistin, enhances insulin sensitivity in liver and skeletal muscle, via an AMPK-dependent pathway in rodent models [24,28]. In humans, the serum concentration of adiponectin is inversely correlated with body mass index (BMI) [32,33] and, most importantly, visceral fat accumulation [34]. Circulating adiponectin levels are reduced in obesity and type 2 diabetes [35]. Thus, adiponectin is negatively associated with insulin resistance in both humans and rodents. Adiponectin reaches a plasma concentration of 2 to $10 \mu \mathrm{g} / \mathrm{mL}$ in humans [36], whereas plasma resistin levels are around $25 \mathrm{ng} / \mathrm{mL}$ in obese patients with diabetes [37]. Thus, adiponectin is the most abundant protein secreted by white adipose tissue. Therefore, we have hypothesized that the effect of resistin depends on the concentration of adiponectin. It has been reported that the expression and secretion of adiponectin is regulated by a variety of hormones and cytokines that influence insulin sensitivity in adipocytes $[38,39]$.

TNF- $\alpha$, a cytokine that induces insulin resistance, functions as a major negative regulator of adiponectin and causes metabolic disorders by impairing the function of adipose tissues [40]. Due to the protective effect of adiponectin against insulin-associated metabolic diseases, TNF- $\alpha$-induced reduction of adiponectin expression is considered a crucial event in the development of insulin resistance. It is well documented that 3- to 4 days of exposure of 3T3-L1 adipocytes to TNF- $\alpha$ causes insulin resistance [41] and that a large decrease in the GLUT4 content plays a major role in the decrease in insulin-stimulated glucose transport [42,43]. Moreover, it has been reported that long-term exposure to TNF- $\alpha$ causes insulin resistance and a decrease in insulin receptor and insulin receptor substrate 1 tyrosine phosphorylation in response to a maximal insulin stimulus in Fao hepatoma cells [44] and L6 myocytes [45], which do not secrete adiponectin. These reports suggest that long-term exposure to TNF- $\alpha$ directly causes insulin

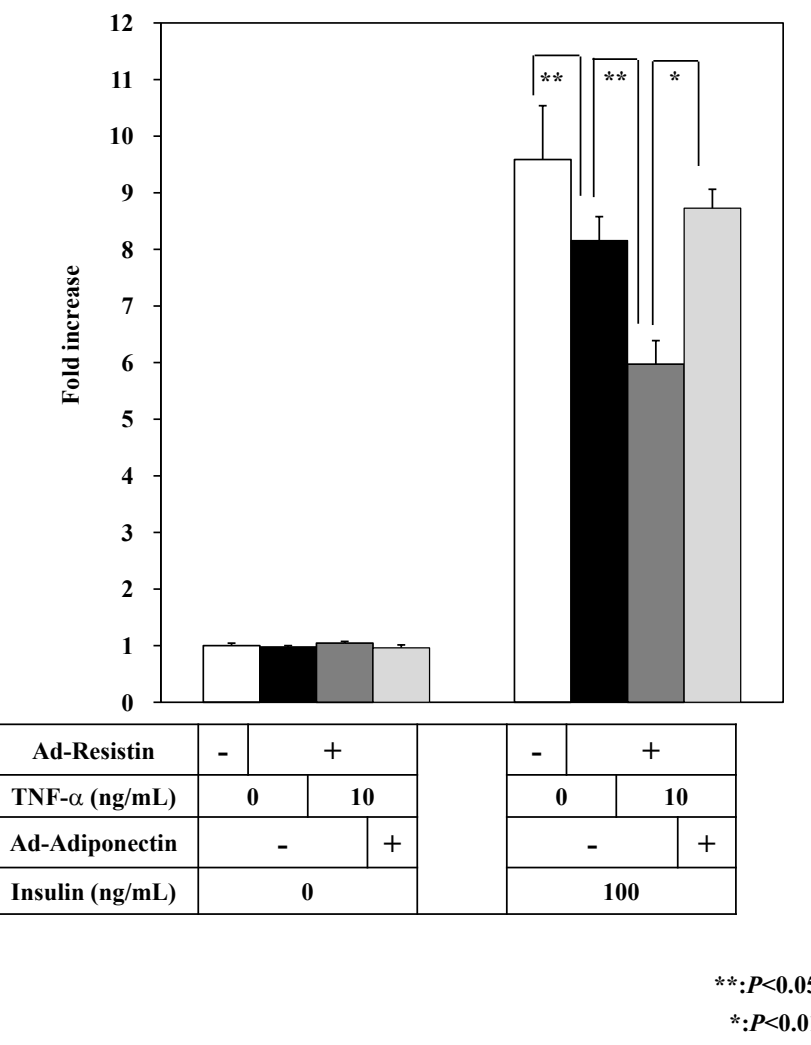

Figure 4: Overexpression of adiponectin prevented synergic effect of resistin and TNF- $\alpha$ in 3T3-L1 adipocytes. 3T3-L1 adipocytes were transduced with Ad-resistin or Ad-lacZ, and Ad-adipo. At $48 \mathrm{hrs}$ after infection, serum-starved 3T3-L1 adipocytes were treated without or with TNF- $\alpha(10 \mathrm{ng} /$ $\mathrm{mL}$ ) for $3 \mathrm{~h}$. These 3T3-L1 adipocytes were treated with insulin $(100 \mathrm{ng} / \mathrm{mL})$, followed by measurement of 2-DOG uptake. Data represent the mean $\pm \mathrm{SE}$ of 3 independent experiments (each experiment performed with 6 samples). ${ }^{\star} P<0.05,{ }^{* *} P<0.01$ 


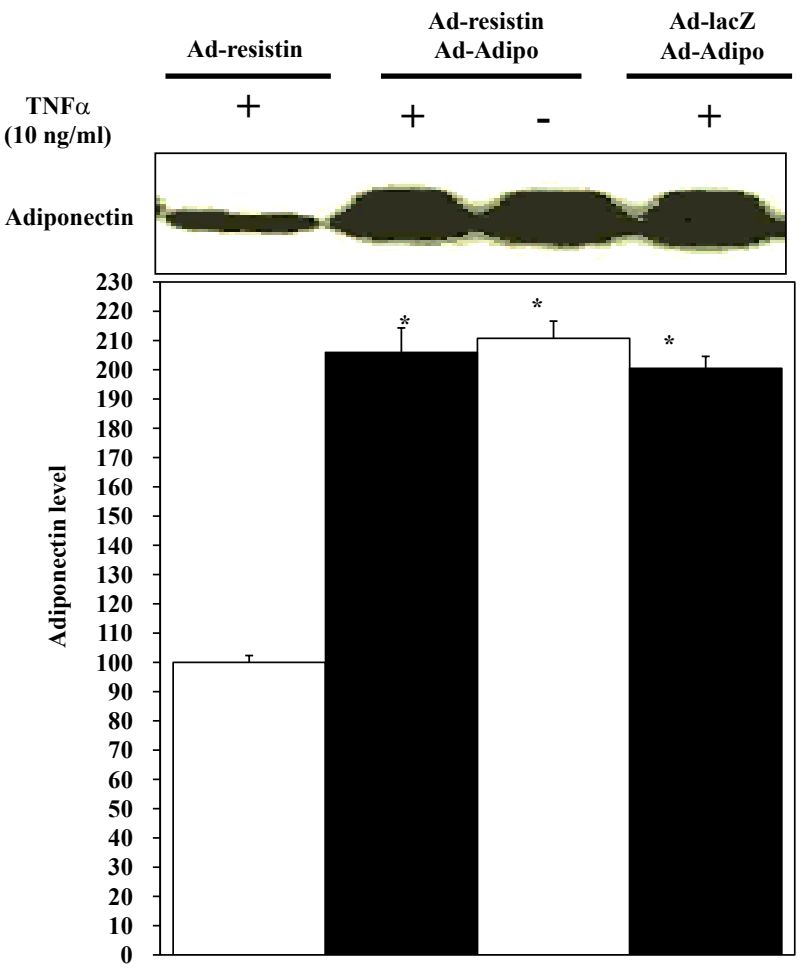

$*: P<0.01$

Figure 5: Reduced adiponectin secretion by treatment with TNF-a is rescued by infection of 3T3-L1 adipocytes with Ad-adipo. 3T3-L1 adipocytes were transduced with Ad-resistin or Ad-lacZ and Ad-adipo. At 48 hrs after infection, 3T3-L1 adipocytes were starved for $3 \mathrm{hrs}$ prior to treatment without or with TNF- $\alpha(10 \mathrm{ng} / \mathrm{mL})$ for $3 \mathrm{~h}$. Conditioned medium was collected, fractionated by sodium dodecyl sulfate-polyacrylamide gel electrophoresis and immunoblotted using a polyclonal antibody against mouse adiponectin to determine the levels of secreted adiponectin. Relative levels of adiponectin released from adipocytes treated with TNF- $\alpha$, as assessed from 4 independent experiments. ${ }^{* \star} P<0.01$.

resistance independent of adiponectin. However, it is still unclear whether short-term treatment with TNF- $\alpha$ causes insulin resistance in 3T3-L1 adipocytes. Therefore, in this study we investigated the shortterm effect of TNF- $\alpha$ on insulin-stimulated 2-DOG uptake in 3T3L1 adipocytes. Our results show that short-term exposure to TNF- $\alpha$ does not affect insulin-stimulated glucose uptake in 3T3-L1 adipocyte, whereas TNF- $\alpha$ decreased the secretion of adiponectin. Adiponectin improves lipid metabolism in adipose tissue, but its beneficial effect on insulin sensitivity can primarily be observed in skeletal muscle cells. Thus, significant impairment in insulin sensitivity is not expected in 3T3-L1 cells due to decrease of adiponectin expression, because adiponectin is the most abundant among other adipocytokines such as TNF- $\alpha$, resistin, and free fatty acids. Therefore, overexpression of resistin exacerbates insulin resistance in the condition of decreased adiponectin levels, emphasizing the importance of reduced adiponectin secretion in resistin- induced insulin resistance, which is underpinned by the fact that TNF- $\alpha$ induced effect of resistin can improved by overexpression adiponectin.

In this study, we have shown that resistin may cause severe insulin resistance under the condition of low adiponectin. The precise role that resistin may play in human pathophysiological states can be determined on the results of future studies measuring resistin and adiponectin levels and the effects of these conditions.

\section{Acknowledgments}

We are indebted to Yuko Ohashi, Emiko Seino, and Atsuko Hashimoto for excellent technical assistance. This work was supported in part by the Salt Science Research Foundation (H.S.), a Grant-in-Aid Challenging Exploratory Research (H.S.) and a Grant-in-Aid Scientific Research (H.S.) from the Ministry of Education, Culture, Sports, Science, and Technology.

\section{References}

1. Kahn BB, Flier JS (2000) Obesity and insulin resistance. J Clin Invest 106 473-481.

2. Wellen KE, Hotamisligil GS (2003) Obesity-induced inflammatory changes in adipose tissue. J Clin Invest 112: 1785-1788.

3. Olefsky JM, Glass CK (2010) Macrophages, inflammation, and insulin resistance. Annu Rev Physiol 72: 219-246.

4. Steppan CM, Bailey ST, Bhat S, Brown EJ, Banerjee RR, et al. (2001) The hormone resistin links obesity to diabetes. Nature 409: 307-312.

5. Rajala MW, Qi Y, Patel HR, Takahashi N, Banerjee R, et al. (2004) Regulation of resistin expression and circulating levels in obesity, diabetes, and fasting Diabetes 53: 1671-1679.

6. Way JM, Görgün CZ, Tong Q, Uysal KT, Brown KK, et al. (2001) Adipose tissue resistin expression is severely suppressed in obesity and stimulated by peroxisome proliferator-activated receptor gamma agonists. J Biol Chem 276 : 25651-25653.

7. Rajala MW, Obici S, Scherer PE, Rossetti L (2003) Adipose-derived resistin and gut-derived resistin-like molecule-beta selectively impair insulin action on glucose production. J Clin Invest 111: 225-230

8. Satoh H, Nguyen MT, Miles PD, Imamura T, Usui I, et al. (2004) Adenovirusmediated chronic "hyper-resistinemia" leads to in vivo insulin resistance in normal rats. J Clin Invest 114: 224-231.

9. Banerjee RR, Rangwala SM, Shapiro JS, Rich AS, Rhoades B, et al. (2004) Regulation of fasted blood glucose by resistin. Science 303: 1195-1198.

10. Muse ED, Obici S, Bhanot S, Monia BP, McKay RA, et al. (2004) Role of resistin in diet-induced hepatic insulin resistance. J Clin Invest 114: 232-239.

11. Savage DB, Sewter CP, Klenk ES, Segal DG, Vidal-Puig A, et al. (2001) Resistin / Fizz3 expression in relation to obesity and peroxisome proliferatoractivated receptor-gamma action in humans. Diabetes 50: 2199-2202.

12. Ochi M, Osawa $H$, Hirota $Y$, Hara K, Tabara $Y$, et al. (2007) Frequency of the G/G genotype of resistin single nucleotide polymorphism at -420 appears to be increased in younger-onset type 2 diabetes. Diabetes 56: 2834-2838.

13. Xu JY, Sham PC, Xu A, Tso AW, Wat NM, et al. (2007) Resistin gene polymorphisms and progression of glycaemia in southern Chinese: a 5-year prospective study. Clin Endocrinol (Oxf) 66: 211-217.

14. Menzaghi C, Coco A, Salvemini L, Thompson R, De Cosmo S, et al. (2006) Heritability of serum resistin and its genetic correlation with insulin resistancerelated features in nondiabetic Caucasians. J Clin Endocrinol Metab 91: 27922795.

15. Conneely KN, Silander K, Scott LJ, Mohlke KL, Lazaridis KN, et al. (2004) Variation in the resistin gene is associated with obesity and insulin-related phenotypes in Finnish subjects. Diabetologia 47: 1782-1788.

16. Lee JH, Chan JL, Yiannakouris N, Kontogianni M, Estrada E, et al. (2003) Circulating resistin levels are not associated with obesity or insulin resistance in humans and are not regulated by fasting or leptin administration: crosssectional and interventional studies in normal, insulin-resistant, and diabetic subjects. J Clin Endocrinol Metab 88: 4848-4856.

17. Nakano Y, Tobe T, Choi-Miura NH, Mazda T, Tomita M (1996) Isolation and characterization of GBP28, a novel gelatin-binding protein purified from human plasma. J Biochem 120: 803-812.

18. Maeda K, Okubo K, Shimomura I, Funahashi T, Matsuzawa Y, et al. (1996) cDNA cloning and expression of a novel adipose specific collagen-like factor apM1 (AdiPose Most abundant Gene transcript 1). Biochem Biophys Res Commun 221: 286-289. 
Citation: Machii N, Satoh H, Kudoh A, Watanabe T (2012) Resistin Exacerbates Insulin Resistance under the Condition of Low Adiponectin in 3T3-L1 Adipocytes. J Diabetes Metab 3: 230. doi:10.4172/2155-6156.1000230

Page 6 of 6

19. Hu E, Liang P, Spiegelman BM (1996) AdipoQ is a novel adipose-specific gene dysregulated in obesity. J Biol Chem 271: 10697-10703.

20. Scherer PE, Williams S, Fogliano M, Baldini G, Lodish HF (1995) A novel serum protein similar to $\mathrm{C} 1 \mathrm{q}$, produced exclusively in adipocytes. J Biol Chem 270: $26746-26749$.

21. Matsuzawa $Y$ (2010) Adiponectin: a key player in obesity related disorders. Curr Pharm Des 16: 1896-1901.

22. Scherer PE (2006) Adipose tissue: from lipid storage compartment to endocrine organ. Diabetes 55: 1537-1545

23. Hotta K, Funahashi T, Bodkin NL, Ortmeyer HK, Arita Y, et al. (2001) Circulating concentrations of the adipocyte protein adiponectin are decreased in parallel with reduced insulin sensitivity during the progression to type 2 diabetes in rhesus monkeys. Diabetes 50: 1126-1133.

24. Satoh H, Nguyen MT, Trujillo M, Imamura T, Usui I, et al. (2005) Adenovirusmediated adiponectin expression augments skeletal muscle insulin sensitivity in male Wistar rats. Diabetes 54: 1304-1313.

25. Fruebis J, Tsao TS, Javorschi S, Ebbets-Reed D, Erickson MR, et al. (2001) Proteolytic cleavage product of $30-\mathrm{kDa}$ adipocyte complement-related protein increases fatty acid oxidation in muscle and causes weight loss in mice. Proc Natl Acad Sci U S A 98: 2005-2010.

26. Yamauchi T, Kamon J, Waki H, Terauchi Y, Kubota N, et al. (2001) The fatderived hormone adiponectin reverses insulin resistance associated with both lipoatrophy and obesity. Nat Med 7: 941-946.

27. Berg AH, Combs TP, Du X, Brownlee M, Scherer PE (2001) The adipocytesecreted protein Acrp30 enhances hepatic insulin action. Nat Med 7: 947-953.

28. Yamauchi T, Kamon J, Minokoshi Y, Ito Y, Waki H, et al. (2002) Adiponectin stimulates glucose utilization and fatty-acid oxidation by activating AMPactivated protein kinase. Nat Med 8: 1288-1295.

29. Hotamisligil GS, Arner P, Caro JF, Atkinson RL, Spiegelman BM (1995) Increased adipose tissue expression of tumor necrosis factor-alpha in human obesity and insulin resistance. J Clin Invest 95: 2409-2415.

30. Maeda N, Shimomura I, Kishida K, Nishizawa H, Matsuda M, et al. (2002) Dietinduced insulin resistance in mice lacking adiponectin/ACRP30. Nat Med 8: 731-737

31. Nguyen MT, Satoh H, Favelyukis S, Babendure JL, Imamura T, et al. (2005) JNK and tumor necrosis factor-alpha mediate free fatty acid-induced insulin resistance in 3T3-L1 adipocytes. J Biol Chem 280: 35361-35371.

32. Matsubara M, Maruoka S, Katayose S (2002) Inverse relationship between plasma adiponectin and leptin concentrations in normal-weight and obese women. Eur J Endocrinol 147: 173-180.
33. Cnop M, Havel PJ, Utzschneider KM, Carr DB, Sinha MK, et al. (2003) Relationship of adiponectin to body fat distribution, insulin sensitivity and plasma lipoproteins: evidence for independent roles of age and sex. Diabetologia 46 459-469.

34. Lara-Castro C, Luo N, Wallace P, Klein RL, Garvey WT (2006) Adiponectin multimeric complexes and the metabolic syndrome trait cluster. Diabetes 55 : 249-259.

35. Weyer C, Funahashi T, Tanaka S, Hotta K, Matsuzawa Y, et al. (2001) Hypoadiponectinemia in obesity and type 2 diabetes: close association with insulin resistance and hyperinsulinemia. J Clin Endocrinol Metab 86: 19301935.

36. Arita Y, Kihara S, Ouchi N, Takahashi M, Maeda K, et al. (1999) Paradoxical decrease of an adipose-specific protein, adiponectin, in obesity. Biochem Biophys Res Commun 257: 79-83.

37. Lu HL, Wang HW, Wen Y, Zhang MX, Lin HH (2006) Roles of adipocyte derived hormone adiponectin and resistin in insulin resistance of type 2 diabetes. World J Gastroenterol 12: 1747-1751.

38. Fasshauer M, Kralisch S, Klier M, Lossner U, Bluher M, et al. (2003) Adiponectin gene expression and secretion is inhibited by interleukin-6 in 3T3L1 adipocytes. Biochem Biophys Res Commun 301: 1045-1050.

39. Chazenbalk G, Trivax BS, Yildiz BO, Bertolotto C, Mathur R, et al. (2010) Regulation of adiponectin secretion by adipocytes in the polycystic ovary syndrome: role of tumor necrosis factor-\{alpha\}. J Clin Endocrinol Metab 95: 935-942.

40. Cawthorn WP, Sethi JK (2008) TNF-alpha and adipocyte biology. FEBS Let 582: 117-131.

41. Hotamisligil GS, Murray DL, Choy LN, Spiegelman BM (1994) Tumor necrosis factor alpha inhibits signaling from the insulin receptor. Proc Natl Acad Sci U S A 91: 4854-4858.

42. Stephens JM, Pekala PH (1991) Transcriptional repression of the GLUT4 and C/EBP genes in 3T3-L1 adipocytes by tumor necrosis factor-alpha. J Bio Chem 266: 21839-21845

43. Hotamisligil GS, Shargill NS, Spiegelman BM (1993) Adipose expression of tumor necrosis factor-alpha: direct role in obesity-linked insulin resistance. Science 259: 87-91.

44. Feinstein R, Kanety H, Papa MZ, Lunenfeld B, Karasik A (1993) Tumo necrosis factor-alpha suppresses insulin-induced tyrosine phosphorylation of insulin receptor and its substrates. J Biol Chem 268: 26055-26058.

45. Begum N, Ragolia L (1996) Effect of tumor necrosis factor-alpha on insulin action in cultured rat skeletal muscle cells. Endocrinology 137: 2441-2446. 